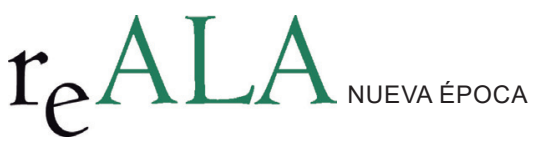

REALA, Nueva Época - N. ${ }^{\circ}$, enero-junio 2016 - ISSN: 1989-8975

DOI: http://dx.doi.org/10.24965/reala.voi5.10346

José Antonio Magdalena Anda

Villalba Coloma Ankersmit Abogados

joseantonio@jmalegal.eu

\title{
Red ferroviaria y transportes ferroviarios. Su carácter sistémico y la necesaria coordinación entre Administraciones Territoriales
}

\section{Resumen}

El carácter sistémico del ferrocarril es consustancial a tan importante modo de transporte, pero no ha sido siempre bien comprendido. La noción de red es conocida por la Economía del Transporte y supone considerar ciertos principios y características de las redes que explican las particularidades de las industrias en red, incluido el ferrocarril. En el ámbito del Derecho, se parte de una previsión constitucional ajena a la realidad ferroviaria. Luego se han desarrollado categorías jurídicas específicas, como las infraestructuras en red, pero dichas construcciones dogmáticas parten de una equiparación entre infraestructura y red que se estima inadecuada o reduccionista. Finalmente, el concepto de red ha sido asumido por el Tribunal Constitucional como elemento funcional que permite delimitar las competencias sobre el ferrocarril, superando criterios formalistas alejados de la realidad. Se concluye que cualquier política sectorial o análisis jurídico del ferrocarril debe tomar en consideración su condición sistémica.

Palabras clave

Red ferroviaria. Sistemas. Infraestructuras. Competencias.

\section{Rail network and rail transports. Their systemic nature and required coordination between Territorial Administrations}

Abstract

Systemic nature of railways is of essence but it has not always been properly understood. Network concept is well known for Transport Economics, it implies certain networks principles and characteristics showing the mechanics of network industries, such as railways. As far a Law is concerned, there is an inadequate constitutional regulation. Later on a specific legal category has been produced, network infrastructures, but it is based in the equivalence between infrastructures and networks, which it is deemed inadequate and reductionist. Finally, the network concept has been assumed by the Constitutional Court, as a functional element to narrow the powers on railways, overcoming any formalist criteria divorced for the reality. In conclusion any sectoral policy or legal analysis of railways must take into consideration their systemic nature.

\section{Keywords}

Rail networks. Systems. Infraestructures. Competences. 
I. LA RELEVANCIA DE LAS REDES DE TRANSPORTE FERROVIARIO Y SU ADECUADO ANÁLISIS INTERDISCIPLINAR. II. EL CARÁCTER SISTÉMICO DEL FERROCARRIL. III. NOCIÓN DE RED Y REDES DE TRANSPORTE, UNA DELIMITACIÓN BÁSICA. IV. REDES, SERVICIOS E INFRAESTRUCTURAS EN RED. V. REDES, SISTEMAS Y SUBSISTEMAS FERROVIARIOS EN ESPAÑA. VI. LA RED FERROVIARIA ESPAÑOLA: DE LA RENI (1987) A LA REFIG (2015). VII. LA DEMORADA CONCRECIÓN DE LA RED FERROVIARIA ESTATAL. CATÁLOGO DE LA RED Y DECLARACIÓN SOBRE LA RED. VIII. EL IMPACTO TERRITORIAL DE LA RED FERROVIARIA Y LA NECESARIA COORDINACIÓN DE LAS REDES ENTRE LAS ADMINISTRACIONES TERRITORIALES. IX. LA DOCTRINA DEL TRIBUNAL CONSTITUCIONAL: STC 118/96 Y 245/2012. LA NOCIÓN DE RED SUBYACENTE EN LA TEORÍA DE LOS TRAMOS FRAGMENTARIOS. X. CONSIDERACIONES FINALES. BIBLIOGRAFÍA.

\section{LA RELEVANCIA DE LAS REDES DE TRANSPORTE FERROVIARIO Y SU ADECUADO ANÁLISIS INTERDISCIPLINAR}

Es lugar común en los estudios del Derecho Económico ${ }^{1}$ enfatizar el carácter estratégico de los transportes, por su carácter instrumental en las relaciones de producción y distribución así como en el desarrollo socioeconómico del territorio. A lo cual se añade la relevancia del transporte como sector en sí mismo considerado, con sus dinámicas y actores propios.

Entre los diversos modos de transporte, el ferrocarril siempre ha destacado por su impacto en el desarrollo de las sociedades en que se introdujo. Desde sus orígenes en España en la primera mitad del XIX, como motor de la revolución industrial, pasando por su sempiterna crisis de finales de siglo y comienzos del siglo XX, su nacionalización en $1941^{2}$, el cambio de modelo impuesto por la Política Común de Transportes a partir de los años noventa del siglo XX, y, por último, la revolución tecnológica que supuso el desarrollo de la alta velocidad en los albores del siglo XXI.

El impacto generado por el transporte en general y por el ferrocarril en particular es considerable y ha sido objeto de numerosos estudios en diversas áreas del conocimiento. Tanto en la ingeniería como en la sociología, la geografía y la economía, donde ha dado lugar a una rama específica: la Economía del Transporte³.

Las innovaciones tecnológicas en este sector han producido una verdadera contracción del espacio, una reducción de las distancias ${ }^{4}$ en términos de costes y tiempos, particularmente entre las ciudades. Se produce una convergencia que reduce costes y por tanto afecta a las relaciones productivas y sociales. Ello ha favorecido fenómenos tales como la especialización y la globalización, dadas las economías de escala que se generan y la ampliación de los mercados posibles.

El ferrocarril, particularmente en los últimos veinte años, ha revolucionado la integración y cohesión económica, social y urbana del territorio. Fenómeno apreciable tanto a nivel nacional, España, como a nivel europeo, donde se ha establecido una Política Ferroviaria Común como instrumento de primer orden para impulsar el mercado único, basado en un sistema de transportes más eficiente, sostenible, multimodal y vertebrador de la Unión 5 . Política comunitaria que desde los años noventa del pasado siglo pivota sobre la apertura a la competencia de los servicios de transporte ferroviario, disociándolos de la gestión de las infraestructuras, creando un nuevo entorno de relaciones jurídicas y económicas. El derecho de acceso a la red se convierte en elemento clave del nuevo sistema, basado en la competencia por el acceso al mercado y, luego, en la supervisión de la gestión del mismo.

Por lo que respecta al ámbito jurídico, aunque el ferrocarril fue el gran catalizador de conceptos jurídicos claves en el desarrollo de nuestro Derecho Administrativo ${ }^{6}$, siempre se ha advertido una cierta incomprensión del

1 Por todos, ARIÑo ORTIZ, LOPEZ DE CASTRO GARCIA-MORENO (2004); con una perspectiva más general, MUÑOz MACHADO (2009).

2 Sobre la historia del ferrocarril en España es destacable por su exhaustividad la obra de ARTOLA M., (1978); más generalista, 150 años del ferrocarril en España, AA.VV., Anaya-Fundación de los Ferrocarriles Españoles, 1998.

3 DE RUS, CAMPOS, NOMBELA (2003).

4 GutieRrez PuEbla (1998).

5 Obligado es referirse a las Redes Transeuropeas (TEN), introducidas en los años noventa del pasado siglo en los sectores del transporte, las telecomunicaciones y la energía, y cuya finalidad es contribuir al desarrollo del mercado interior y reforzar la cohesión económica y social. Consagradas en los artículos 170 a 172 y 194, apartado 1, letra d), del Tratado de Funcionamiento de la Unión Europea, su regulación actual por lo que al transporte se refiere (TEN-T) se contiene en el Reglamento (UE) n. ${ }^{\circ}$ 1315/2013 del Parlamento Europeo y del Consejo, de 11 de diciembre de 2013, sobre las orientaciones de la Unión para el desarrollo de la Red Transeuropea de Transporte, conocido como "Reglamento de Orientaciones”. Este reglamento define el diseño de la red, con los correspondientes mapas, requisitos técnicos, y previsiones temporales de implantación, con especial énfasis en la interconexión de los nodos urbanos.

6 Sigue siendo un referente indispensable la obra de BERMEJO VERA (1975).

REALA, Nueva Época, - N. ${ }^{\circ}$ 5, enero-junio 2016 - ISSN: 1989-8975 - DOI: 10.24965/reala.voi5.10346 
fenómeno ferroviario, tanto en las políticas como en las reglamentaciones aprobadas sucesivamente ${ }^{7}$. Obsesionados primero con la creación de una red ferroviaria que alcanzase todo el territorio, y luego con evitar su quiebra y hacerlo viable, los poderes públicos apenas esbozaron un régimen jurídico que fuera más allá del aspecto material de la obra pública ferroviaria, manteniendo durante 65 años una situación monopolística basada en una concepción unitaria del ferrocarril.

En el presente trabajo se pretende un acercamiento interdisciplinar a un concepto clave para el transporte ferroviario cual es la noción de red. Una propiedad innata a todo sistema ferroviario, que aun estando ligado a las infraestructuras ferroviarias, tiene entidad propia. Puesto que en nuestro ordenamiento jurídico no existe una definición legal unívoca y generalista de qué sea una «red», ha de estarse a las definiciones sectoriales que se fueron aprobando (en los llamados sectores regulados, energía, telecomunicaciones, transporte, etc.) y al uso administrativo del término, asimilado o equiparado al de infraestructura.

Intentaré arrojar algo de luz sobre la verdadera naturaleza de qué sea una red ferroviaria y qué relaciones mantiene tiene con las voces «sistema» e «infraestructura»; sólo de una correcta comprensión de la naturaleza del transporte ferroviario y del correcto empleo de tales términos puede abordarse, con rigor, el ferrocarril como fenómeno jurídico. Se hará uso, al efecto, de conceptos y teorías propias de la Economía del Transporte y de la Teoría de Sistemas, con apoyo en los estudios ya existentes sobre el impacto territorial del ferrocarril.

\section{EL CARÁCTER SISTÉMICO DEL FERROCARRIL}

Cualquier análisis, técnico o jurídico, del ferrocarril debe partir de su innato y consustancial carácter sistémico. Es una característica propia y peculiar del transporte en general y del ferrocarril en particular, y debería condicionar el diseño de cualquier política o regulación sobre el mismo, aunque no siempre sea así.

Sistémico alude y refiere la existencia de un sistema, lo que obliga a considerar tal concepto. Etimológicamente hablando, un sistema es un conjunto de elementos ordenadamente relacionados entre sí, con una funcionalidad característica. El Diccionario de la Real Academia así lo describe ${ }^{8}$, referenciándolo en sus diversas acepciones a un conjunto de unidades relacionadas entre sí.

La idea clave definidora de un sistema es la interrelación dinámica de los elementos que lo componen, lo que permite afirmar que un sistema es algo más que la mera suma de sus elementos. Por tanto, un sistema no es un simple conjunto de unidades singulares, no es una mera agregación de elementos individuales, sino que es algo más, debido a las relaciones que se crean entre sus componentes.

De la importancia del sistema como concepto útil para las ciencias, tanto físicas como sociales ${ }^{9}$, da buena cuenta la existencia de una Teoría General de Sistemas, creada por el científico Leopold von Bertalanffy ${ }^{10}$. Una teoría interdisciplinar que ha dado un gran juego en diversos campos y que sentó los fundamentos para el análisis y clasificación de los sistemas, como realidades presentes en cualquier área del conocimiento y de las actividades humanas. Puede distinguirse así entre sistemas reales y lógicos, siendo los primeros aquellos en los que existe verdadera actividad en el plano físico, que surgen de las cosas mismas objeto de estudio. Por lo mismo que cabe diferenciar entre sistemas abiertos y cerrados, en función de su capacidad de interactuar con el entorno.

Desde esta perspectiva, el transporte es un sistema real y concreto (conjunto de elementos que ordenan la actividad de transporte), artificial (en sentido opuesto a natural) y abierto (admite relaciones con su entorno). Afirmación que no es especulativa sino descriptiva: la sistematicidad del transporte es su rasgo característico, sin perjuicio de las variantes que presente cada subsector o diferente modo de transporte, impuestas por la tecnología. La realidad socioeconómica del transporte obliga a considerarlo como un sistema, aserto plenamente asumido por la doctrina científica".

Como consecuencia del carácter sistémico la actividad del transporte tiende a la superación de los límites territoriales y, además, es sensible a cualquier intervención sobre sus elementos. Ello obliga a formular modelos de sistemas de transporte, a diseñarlos de manera que se busque la máxima eficiencia y coordinación con los modos de producción y de distribución de la economía en que operan.

7 El ferrocarril tuvo una tardía y accidentada implantación y desarrollo en la España del XIX, en todos los órdenes, desde la perspectiva institucional, empresarial e incluso militar.

8 Acepción n. ${ }^{\circ}$ 7. “f. Conjunto de elementos organizados para determinado fin.", Diccionario de la lengua española, edición tricentenario, http://dle.rae.es/?id=VXs6SD8 (consultado el 17-02-2016).

9 Jurídicamente es clásico referirse al ordenamiento jurídico como "sistema jurídico", SANTAMARÍA PASTOR (1991).

10 García CuAdRAdo (1995).

11 Voigt (1964); De Rus, CAMPOS, NOMBELA (2003): pág. 931.

REALA, Nueva Época, - N. ${ }^{\circ}$ 5, enero-junio 2016 - ISSN: 1989-8975 - DOI: 10.24965/reala.voi5.10346 
La coordinación, por tanto, resulta una nota o requisito exigido por la propia naturaleza sistémica del transporte: desde el momento mismo que en todo transporte precisa del uso de una infraestructura, deviene esencial concebirlo como un sistema integrado que posibilite el mejor uso de la infraestructura y minimice el coste generalizado total para la colectividad. Esta es una de las razones por las cuales siempre se ha justificado la intervención administrativa en la actividad del transporte, en sus distintos modos.

Claro está que hasta aquí nos movemos en un plano general, el más amplio, en el cual la noción sistema de transporte abarca a todos los modos (terrestre, aéreo y marítimo). Ese sistema general puede descomponerse en sistemas de ámbito modal o territorial más reducido. Ello explica las constantes referencias en las leyes sobre transporte al «sistema común» ${ }^{12}$, como una suerte de marco general en el que se inserta el sistema de transporte concreto a regular y a cuyo beneficio o máxima operatividad deben conducir cada sistema modal.

Por lo que respecta al ferrocarril puede definirse técnicamente como «un sistema complejo» formado por numerosos elementos que deben ser coherentes y funcionales entre sí, en palabras del grupo de expertos nombrados en Agosto de 2013 por el Ministerio de Fomento para evaluar la situación del ferrocarril y proponer mejoras ${ }^{13}$.

La singularidad que presenta el ferrocarril es la especial vinculación entre la actividad de transporte y la infraestructura ferroviaria, que ha condicionado seriamente su régimen jurídico desde sus inicios en el siglo XIX.

La naturaleza dual del ferrocarril, como servicio de transporte y como infraestructura viaria, se caracteriza por una exigencia absoluta de coordinación y compatibilidad entre vehículo e infraestructura viaria, no presente en otros modos. Como certeramente ha expuesto CARBONELL PORRAS ${ }^{14}$ existe una diferencia sustancial entre el transporte por carretera y el ferroviario, cual es la especial intensidad del uso que de la infraestructura viaria exige cada modo de transporte. En la carretera nos encontramos ante un uso común del dominio público, abierto y sin necesidad de una gestión de la capacidad, mientras que en el ferrocarril ese uso es de una especial intensidad que exige un regulador o gestor de la infraestructura e impone unos especiales requisitos de acceso ${ }^{15}$.

Llegados a este punto, y a poco que se haya consultado la bibliografía económica, se observará una rápida identificación o un uso indistinto de la expresión «red de transporte» y «sistema de transporte», uso que se ha traspasado al ámbito jurídico. Puesto que el correcto uso del lenguaje es esencial en cualquier rama del saber y, aún más, en la ciencia jurídica, obligado resulta aclarar la relación entre los términos red y sistema.

No todo sistema es una red pero sí toda red es un sistema ${ }^{16}$. Las redes son sistemas que presentan ciertas características en cuanto a sus elementos y las funciones y relaciones que desarrollan.

En el concreto sector del transporte, el mismo es definido por la ciencia económica como una economía o industria en red ${ }^{17}$. No existe duda de que el sistema de transporte se expresa como una red de transporte, cuyos elementos básicos son los siguientes ${ }^{18}$ : operadores (empresas de transporte), equipo móvil (vehículos), infraestructura (vías, caminos, estaciones, etc.), superestructura (sistemas de información y navegación) y usuarios (viajeros, cargadores, etc.).

En similares términos se pronuncia la doctrina jurídica sobre el transporte que considera a la red como una parte fundamental del sistema ${ }^{19}$, junto con los modos (medio técnicos o vehículos) y las empresas (operadores del transporte).

Ahora bien, sucede que este tratamiento jurídico parte de equiparar la red con la infraestructura viaria, hasta el extremo de haber desarrollado un concepto ad hoc que ha hecho fortuna: las infraestructuras en red. Considero que se está produciendo cierto confusionismo sobre qué sea una red y su relación con las infraestructuras qué la soportan o sobre las que se configura la red misma, y a ello dedico los siguientes epígrafes.

12 Artículo $3 .{ }^{\circ}$ de la ley $16 / 1987$ de Ordenación de los Transportes Terrestres; artículo $4 .{ }^{\circ}$ de la Ley $39 / 2003$ del Sector Ferroviario y mismo precepto en Ley 38/2015.

13 Informe de la Comisión técnico-científica para el estudio de mejoras en el sector ferroviario, Centro de Publicaciones del Ministerio de Fomento, edición digital Junio 2014, (http://www.fomento.gob.es/nr/rdonlyres/f2306101-f215-4c10-a121-6d6afo83d453/125370/informecomi si\%C3\%B3nt\%C3\%Agcnicocientificasectorferroviario1.pdf).

14 CARBOnell PORRAS (2014): págs.916-919.

15 Sin que pueda perderse de vista que lo esencial jurídicamente es el servicio de transporte, por encima de la relación jurídica subyacente que ese servicio tenga con la infraestructura demanial por la que discurre. Un aserto ya establecido por el Prof. GARCIA DE ENTERRíA (1953).

16 Es esta una afirmación asumida por la generalidad de la doctrina económica. Sobre la dinámica de las redes en el ámbito sociológico y económico, BATTEN, CASTI, THORD (2012).

17 RUS, CAMPOS, NOMBELA (2003): págs. 50 y ss.

18 DE RUS (2001): págs.134-135.

19 ARIÑo ORTIZ, LOPEZ De CAStro GARCIA-MORENo (2004): págs. 9312-933; Bermejo Vera (1999): págs. $281-282$.

REALA, Nueva Época, - N. ${ }^{5}$ 5, enero-junio 2016 - ISSN: 1989-8975 - DOI: 10.24965/reala.voi5.10346 


\section{NOCIÓN DE RED Y REDES DE TRANSPORTE, UNA DELIMITACIÓN BÁSICA}

La idea de red es intuitiva para el ser humano, que la emplea de diversas maneras en los más distintos ámbitos. Se habla de redes de transporte, de información, de inteligencia y, como no, de redes sociales. Cada acepción ha dado lugar al desarrollo de teorías específicas para esos fenómenos ${ }^{20}$. Obviamente, las acepciones más o menos informales o vulgares no resultan útiles para avanzar en el análisis del ferrocarril, por lo que ha de establecerse un concepto riguroso del que partir.

El término red se refiere a un conjunto de entidades conectadas entre sí, cuya disposición permite la circulación de elementos (materiales o inmateriales) entre aquéllas, conforme a reglas definidas. Esta definición parte de caracterizar a la red como sistema, como ya se expuso, así que han de concretarse sus elementos y principios característicos.

Matemáticamente las redes se representan mediante grafos ${ }^{21}$, integrados por nodos y por conexiones entre estos. Por tanto, una red es un conjunto de nodos y los vínculos o conexiones entre ellos; conexiones que pueden ser reales o potenciales, pues no todas las posibles llegarán a constituirse en función de su coste y del modelo de red que se implante.

Lo relevante es la estructura que adopten esas relaciones entre los nodos, pues eso incide en el flujo y/o capacidad de transmisión de elementos de un nodo a los demás. El diseño de la red (la formulación del modelo de red) deviene fundamental para comprender su funcionamiento y potencialidad.

Ello obliga a considerar ciertas características propias de las redes: la conectividad y la jerarquía. Se entiende por conectividad la capacidad para conectar los nodos entre sí, lo cual permite atendiendo al número de conexiones de cada nodo jerarquizar la importancia de cada uno (principio de jerarquía). Ambas características están ligadas a su vez al de la coherencia de los elementos de la red, es decir que no existan obstáculos técnicos que impidan el flujo entre los nodos.

Si se desciende de lo genérico a lo concreto y al sector del transporte, han de considerarse a los nodos como paradas y las conexiones como rutas ${ }^{22}$. El diseño de una red de transporte habrá de considerar tanto el número de nodos como la conectividad de cada nodo, lo que es tanto como decidir qué tipo de rutas priorizar, directas o indirectas.

De esta manera, un diseño centro-radial (el típico español desde el XIX) se basa en potenciar ciertos nodos (aeropuertos o estaciones como «hubs» en la terminología sectorial) dotándoles de numerosas conexiones (rutas) para desde allí distribuir tráficos a los nodos periféricos. Un modelo que refleja una estrategia óptima para el constructor-gestor de las infraestructuras, pero menos atractivo para los usuarios, y que además conlleva posibles problemas de congestión.

Como ya se ha indicado, al ser el transporte, en palabras de los economistas, una industria en red produce efectos de notable impacto en cuanto a la eficiencia del transporte mismo. El diseño de las rutas, su conectividad (que supone la necesaria interoperabilidad entre vehículos y vías) y la consiguiente jerarquización de los nodos, provocará un mayor o menor flujo de viajeros y mercancías, generará problemas de congestión o los reducirá. Circunstancias que, además, permitirán o impedirán la interconexión de cada red de transporte con otras, del mismo o de diferente modo, lo que a su vez puede potenciar esos otros modos con efectos acumulativos en la economía. Por obvio que resulte, el entorno económico internacional favorece la creación y consolidación de cadenas de transporte multimodales, por lo que dar acceso ferroviario eficiente a los puertos de interés general y a los principales centros logísticos del país es ya un objetivo estratégico ${ }^{23}$.

Al hilo de lo anterior, y por eso mismo, en las redes de transporte deben considerarse los llamados efectos de red o economías de red que supone la existencia de externalidades positivas de uso ${ }^{24}$. No es sólo que se produzcan economías de escala, que también, sino que se producen economías de densidad, donde a mayor número de usua-

20 La bibliografía sobre las redes en los distintos campos científicos es abundantísima; a modo puramente enunciativo: desde perspectiva general la obra ya citada de BATTEN, CASTI, THORD (2012); en el ámbito de la geografía GUTIÉRREZ PUEBLA (1998), en el campo de la investigación y la economía del conocimiento, KOSCHATZKY (2002): 15-26.

21 Solana Alvarez, Orero Gimenez (2008): 679-686.

22 DE RUS (20019: 124-153.

23 Existe una gran diversidad de nodos logísticos: centros de transporte por carretera, terminales ferroviarias de ADIF, terminales ferroportuarias, puertos secos y terminales marítimas interiores, zonas de Actividad Logística, centros de carga aérea (fuente: Estrategia Logística de España, Ministerio de Fomento; http://www.fomento.gob.es/NR/rdonlyres/9F137531-A314-433C-B377-E8A3F59572F5/121814/20131125Estrate giaLogistica.pdf).

24 Sobre los efectos de red, desde un punto de vista económico, BELL, CALZADA, ESTRUCH MANJón, (2009); también en DE Rus, CAMPOS, NOMBELA (2003).

REALA, Nueva Época, - N. 5, enero-junio 2016 - ISSN: 1989-8975 - DOI: 10.24965/reala.voi5.10346 
rios mayor utilidad, o dicho de otra manera los costes variables medios de la empresa de transporte decrecen cuando aumenta la densidad del servicio de transporte. Eso puede conseguirse bien incrementando los tráficos por ruta o ampliando la capacidad de carga de los medios (ej. Una composición de trenes más largos), de manera tal que no es preciso la apertura de nuevas rutas. No es este el lugar para exponer los principios básicos de la economía del transporte, pero desde luego habrán de tenerse presentes en cualquier política legislativa sobre cada modo.

Llegados a este punto, delimitado el concepto y características de red y de red de transporte, procede analizar su relación con la infraestructura, en tanto que elemento integrante de aquélla.

\section{REDES, SERVICIOS E INFRAESTRUCTURAS EN RED}

Ciertamente el flujo de tráficos entre los nodos debe realizarse sobre un soporte físico, y ese soporte lo conforman las infraestructuras de transporte. Sobre el régimen jurídico de las mismas se ha escrito mucho ${ }^{25}$, existiendo una posición común de su esencialidad, su carácter demanial tradicional en nuestro ordenamiento jurídico y su elevado coste, con las limitaciones que ello impone a la hora de planificar su construcción. No existe la flexibilidad ni permeabilidad propia de las redes de comunicaciones. Aquí las inversiones son costosísimas y generan costes hundidos de inviable recuperación, por lo que se puede hablar de políticas o decisiones cautivas, que una vez adoptadas cierran la vía a otras alternativas, condicionando el futuro desarrollo de la red.

Quisiera detenerme en este estudio en la consideración de las infraestructuras ferroviarias como una red y hasta qué punto cabe asimilar ambos términos. Términos que en el plano jurídico no cuentan con una definición rigurosa y general sino casuística.

Atendiendo a las diversas normas aprobadas sucesivamente en los últimos 40 años, podemos colegir que por red ferroviaria se considera el conjunto de instalaciones e infraestructuras que conforman la línea por donde circulará el tren. No se diferencia a estos efectos entre el plano físico o material de la obra pública a construir o construida y el plano superior de la organización o diseño de los servicios de transporte. Pero es que el concepto jurídico mismo de infraestructura ferroviaria ha sido de muy tardía factura en el ordenamiento jurídico español ${ }^{26}$, introducido en el Título II de la Ley 39/2003 del Sector Ferroviario pues hasta entonces las definiciones de los textos normativos eran meras relaciones de elementos físicos, dispersas y a veces no coincidentes por entero. Definición legal que, por cierto, se engarza necesariamente con la definición que el artículo $4 .^{\circ}$ de dicha Ley realiza de la «red ferroviaria de interés general» identificada con las infraestructuras ferroviarias.

Al respecto, desde el ámbito comunitario resulta obligado señalar que ya desde un primer momento el concepto relevante (casi único empleado) fue el de infraestructuras ferroviarias. Así se desprende del contenido del veterano Reglamento 2598/1970 de la Comisión sobre las infraestructuras ferroviarias y del que en la redacción originaria de la conocidísima Directiva 91/440/CEE del Consejo sobre el desarrollo de los ferrocarriles comunitarios no se mencionó el concepto de red como tal. Fue con la creación de las Redes Transeuropeas del Transporte en los años noventa cuando el vocablo «red» es empleado profusamente, desde los Tratados al Derecho derivado, hasta llegar a la vigente Directiva 2012/34/UE del Parlamento Europeo y del Consejo por la que se establece un espacio ferroviario europeo único, norma señera que define a la red como «toda la infraestructura ferroviaria gestionada por un administrador de infraestructuras».

Esa equiparación normativa ha ido pareja en la doctrina científica que ha identificado red con infraestructura. Y cierto es que dada la especial vinculación entre los servicios de transporte ferroviario y la infraestructura ferroviaria, parece razonable equiparar ambos términos.

Tan es así que se ha creado una categoría jurídica específica basada en esa asimilación: las infraestructuras en red $^{27}$, de las cuales el ferrocarril ha sido utilizado como ejemplo paradigmático, del mismo modo que tradicionalmente se puesto como caso típico de monopolio natural ${ }^{28}$. Por tales infraestructuras en red se entienden aquéllas «instalaciones de valor estratégico, ramificadas por el territorio y con conexión física entre sus extremos, caracterizadas por configuración unitaria al estar entrelazadas, su capacidad limitada y su duplicación antieconómica» por lo cual «constituyen conductos de paso obligado para participar en un determinado mercado de interés general» 29.

Infraestructuras de altísimo coste de construcción, carácter estratégico para la vertebración del transporte, con carácter arterial y una capacidad limitada, lo que obliga a regular y controlar de manera unitaria el acceso a

25 Rivas Castillo, Valcarcel Fernández (2014); Ariño Ortiz (2001); Montoro Chiner(1999).

26 RIVAS CASTILLO (2007): 171-173.

27 Seguimos en este punto la obra de CABALLERO SÁNCHEZ (2003).

28 Sobre el ferrocarril como monopolio natural, OLMEDO GAYA (2000): 267 y ss.

29 CABALLERO SÁNCHEZ (2003): 151.

REALA, Nueva Época, - N. ${ }^{\circ}$ 5, enero-junio 2016 - ISSN: 1989-8975 - DOI: 10.24965/reala.voi5.10346 
la misma. Ello explica el específico régimen jurídico de estas infraestructuras, basado en su naturaleza demanial y por tanto en unas facultades exorbitantes de la Administración titular de las mismas para su adecuada protección y explotación.

Sin embargo, y aun cuando en la formulación de esa categoría jurídica la noción de red es esencial, debo objetar a su equiparación plena con las infraestructuras ferroviarias.

Una cosa es que el ferrocarril precise e imponga un funcionamiento coordinado entre el transporte y la vía (por simplificar las expresiones), hasta el extremo de que el acceso a esa infraestructura en red esté regulado y controlado por la Administración. Pero otra bien diferente son el conjunto de servicios ferroviarios posibles y que se autoricen sobre aquélla infraestructura en red, y que precisa además de unos sistemas de información esenciales (de navegación, comunicación y gestión del tráfico).

El conjunto de los servicios ferroviarios (principales, accesorios y complementarios) es cambiante, flexible y puede coordinarse con otras redes de distinto ámbito geográfico o incluso de otros modos de transporte. Siquiera sea por una cuestión de rigor técnico, es posible hablar de redes de transporte ferroviario superpuestas a las infraestructuras en red existentes. La mera construcción de una línea ferroviaria por sí misma no genera una red de transporte. Precisa de su inserción en una malla de líneas, con conexión a unas instalaciones físicas y engarce con ciertos sistemas de información, así como un operador del transporte que organice y ejecute los tráficos, transformando un mercado potencial de usuarios (cargadores, viajeros, industrias, etc.) en uno real.

A estos efectos resulta ilustrativo revisar la clasificación y los estudios que sobre tráficos ferroviarios en España se han ido produciendo, tanto por el Ministerio de Fomento como por otros organismos, públicos y privados ${ }^{30}$. Los mapas técnicos así generados muestran el distinto alcance entre la infraestructura ferroviaria construida y los flujos principales de tráficos ferroviarios e intermodales, y su evolución a lo largo del tiempo.

Ciertamente, la red o redes ferroviarias españolas dependen directamente de las infraestructuras ferroviarias construidas o por construir y quién sea su operador delimitará las condiciones de acceso a las mismas y/o su ampliación, modificación o reducción. Pero no cabe equiparar red con infraestructura pues aquélla es algo más. Un plano, físico o estructural, son las líneas o tramos de líneas y otro plano bien distinto es el conjunto de servicios que se prestan mediante la asignación de capacidad de esa infraestructura.

Una diferenciación entre servicio e infraestructura que ha dado lugar a otra categoría jurídica singular: los servicios en red $^{31}$, donde lo relevante es la actividad a desarrollar sobre la infraestructura que actúa de soporte. Se trata de una sutil diferenciación jurídica, tan sutil que es rayana en la confusión cuando se refiere a las infraestructuras ferroviarias, que son por definición infraestructuras en red.

En cualquier caso, la relevancia de estas categorías estriba en poner de manifiesto la importancia y carácter diferenciador de la noción de red. En ambas categorías lo verdaderamente significativo, el término y concepto que sustenta la categoría jurídica esbozada, es la red, con sus características propias que condicionan la actividad de transporte (real o potencial).

\section{REDES, SISTEMAS Y SUBSISTEMAS FERROVIARIOS EN ESPAÑA}

Como ya se expuso, una de las características propias de toda red es su conectividad (y el consiguiente requisito de coherencia de sus elementos) y por eso tanto en el ámbito de la Unión Europea como en el español uno de los objetivos a conseguir es el de la máxima interoperabilidad de las distintas redes ferroviarias existentes.

Debido al desarrollo histórico del ferrocarril en cada país, cada red ferroviaria fue concebida según esquemas nacionales, generándose así diferencias técnicas (ancho de vía, electrificación, señalización, gálibo, etc.) que impiden o limitan los tráficos entre dichas redes. En cualquier caso, el esfuerzo realizado por las administraciones comunitarias y nacionales ha permitido una progresiva estandarización de medios, sistemas y equipos, que nos permite interpretar y comprender cómo se vertebra un sistema ferroviario ${ }^{32}$.

30 Son ilustrativos, el PLAN DE INFRAESTRUCTURAS, TRANSPORTE Y VIVIENDA PITVI (2012-2024), formulado por Resolución de 5 de Mayo de 2005 de la Secretaría de Estado de Infraestructuras, Transporte y Vivienda, Ministerio de Fomento (http://www.fomento.gob.es/ MFOM/LANG_CASTELLANO/PLANES/PITVI/PITVI_DOCU/); "Informe sobre la competencia en el transporte de mercancías de por ferrocarril en España”, Comisión Nacional de la Competencia (http://www.cnmc.es/Portals/o/Ficheros/Promocion/Informes_y_Estudios_Sectoriales/2013/ CNC_TRANSPORTE\%2OFERROCARRIL.pdf); Informe de la Comisión técnico-científica para el estudio de mejoras en el sector ferroviario, Centro de Publicaciones del Ministerio de Fomento, 2014 ya citado.

31 LOPEZ-JURADO (2009).

32 Para la redacción de este apartado se ha tenido en consideración el contenido de las Especificaciones Técnicas de Interoperabilidad de la Comisión, el Real Decreto 1434/2010, de 5 de noviembre sobre interoperabilidad del sistema ferroviario de la Red Ferroviaria de interés

REALA, Nueva Época, - N. ${ }^{\circ}$ 5, enero-junio 2016 - ISSN: 1989-8975 - DOI: 10.24965/reala.voi5.10346 
Todo sistema ferroviario se puede descomponer en redes, sistemas y subsistemas, atendiendo al objeto de transporte, condiciones de la infraestructura, alcance geográfico y requerimientos técnicos. De tal modo que podría establecerse el siguiente esquema conceptual:

- El sistema ferroviario o red ferroviaria, en el sentido general de las noemas, se integra por las infraestructuras ferroviarias al uso (líneas, estaciones, terminales y equipamientos fijos) que permitan la operativa del transporte sobre las mismas.

- Por su alcance geográfico, la red ferroviaria puede ser transeuropea o nacional, y en un plano más concreto cabe hablar de redes de ámbito estatal o regional (autonómicas) ${ }^{33}$. En el caso español cabría distinguir entre el sistema ferroviario de titularidad estatal (compuesto por varias redes, que curiosamente incluye la red de cercanías, de ámbito netamente metropolitano) y los sistemas o redes ferroviarias autonómicas 34 .

- A su vez las redes ferroviarias españolas permiten una subdivisión peculiar basada en la coexistencia de tres anchos de vía distintos: red convencional $(1.668 \mathrm{~mm})$, red estándar (1465 mm) y red de ancho métri$\operatorname{co}(1.000 \mathrm{~mm})^{35}$.

- Por su objeto, las redes ferroviarias puede ser de viajeros, de mercancías y mixtas (permiten tráficos de viajeros y de mercancías). En estas redes se consideran incluidos tanto la infraestructura básica (líneas, estaciones, terminales, talleres, etc.) como los sistemas de gestión del tráfico, de posicionamiento y de navegación, instalaciones técnicas de tratamiento de datos y de telecomunicaciones.

- Desde el punto de vista operativo, el sistema ferroviario se subdivide en dos grandes subsistemas: los de carácter estructural y los de carácter funcional. Ente los subsistemas estructurales están: la infraestructura, energía, control-mando y señalización en tierra, control-mando y señalización a bordo y material rodante. Los subsistemas de carácter funcional son el de explotación y gestión del tráfico, el mantenimiento y el de aplicaciones telemáticas para servicios de viajeros y de transporte de mercancías.

La dualidad infraestructura-transporte está presente en todo momento. Para que una red ferroviaria sea operativa es preciso la conjunción de ambos planos, pues una línea por si sola no genera una red de transporte. Es más, técnicamente una línea ferroviaria se compone -más allá de lo que intuitivamente sugiere el nombre- tanto del subsistema estructural (plataforma de vía, carriles, explanación, etc.) como de uno o varios subsistemas funcionales.

Asimismo, debe destacarse el énfasis de las normas reglamentarias y técnicas en establecer y garantizar la «coherencia» del sistema ferroviario, entre la vía y los medios, dado que de ella dependerán los niveles de las prestaciones posibles, como las condiciones de seguridad, la calidad de servicio y su coste. Coherencia que conforma una de las características propias y típicas de toda red, y especialmente de las redes de transporte como expusimos anteriormente.

\section{LA RED FERROVIARIA ESPAÑOLA: DE LA RENI (1987) A LA REFIG (2015)}

Desde 1978 han sido tres las Leyes sectoriales que han regulado el sistema ferroviario español: la Ley 16/1987 de Ordenación de los Transportes Terrestres (LOTT), la Ley 39/2003 del Sector Ferroviario y la reciente Ley $38 / 2015$ del Sector Ferroviario. Cada una con diversa fortuna pero compartiendo unos mismos fundamentos, intentando establecer un marco normativo que se ajuste a la específica naturaleza del sector de transportes por su carácter estratégico para la economía y la vertebración territorial del país.

En dichas normas se introdujo como elemento clave para articular el modelo ferroviario una definición legal de qué sea o qué comprende la red ferroviaria estatal. Definición que fue modificada en mayor o menor medida en cada Ley al socaire de los pronunciamientos del Tribunal Constitucional sobre las competencias propias del Estado por comparación con las de las Comunidades Autónomas.

general, la Orden FOM/167/2015, de 6 de febrero, por la que se regulan las condiciones para la entrada en servicio de subsistemas de carácter estructural, líneas y vehículos ferroviarios.

33 Dejamos a un lado las redes locales, fundamentalmente los sistemas tranviarios y ferrocarriles ligeros que disponen de un régimen jurídico particular.

34 Básicamente son los ferrocarriles de Cataluña, País Vasco, Valencia y Mallorca, donde a partir de la transferencia de los ferrocarriles estatales, en gran medida de vía estrecha, se han desarrollado redes de ámbito regional.

35 El ancho convencional es conocido popularmente como ancho ibérico o "ancho RENFE", de seis pies castellanos adoptado por Real Orden de 31 de Diciembre de 1844. El ancho estándar es el empleado para la Alta Velocidad (factible también para la tecnología TALGO) y a veces es referido como ancho UIC o internacional aunque ello no es exacto. El ancho métrico corresponde a la conocida como "vía estrecha", cuya presencia actual se mantiene principalmente en la cornisa cantábrica, León y Valencia.

REALA, Nueva Época, - N. ${ }^{\circ}$ 5, enero-junio 2016 - ISSN: 1989-8975 - DOI: 10.24965/reala.voi5.10346 
Así, en el artículo 155 de la LOTT se estableció la denominada «Red Nacional Integrada» (RENI o RNI como era referida en el sector), que comprendía «Las líneas y servicios ferroviarios de transporte público que deban formar parte de la estructura básica del sistema general de transporte ferroviario, así como aquellos cuya adecuada gestión exija una explotación conjunta con los anteriores o en los que dicha explotación conjunta resulte necesaria para el correcto funcionamiento del referido sistema general de transporte». Una definición con vocación de máxima aplicabilidad, comprensiva tanto de las infraestructuras ferroviarias (aun cuando su concreción distaba mucho que desear pues parecía limitarse a las líneas férreas) como de los servicios de transporte sobre las mismas. La idea del legislador en ese momento era, claramente, establecer un sistema ferroviario general unitario, basado en una concepción amplia de la red ferroviaria que se superpusiera a cualquier otra red de menor alcance. Una base teórica en línea con la posición mayoritaria de la doctrina ${ }^{36}$.

La concepción del ferrocarril en la LOTT mantenía la tradicional visión de unidad vehículo-vía que imponía una unidad de explotación, razón por la cual los cambios introducidos por la Política Común de Transportes a partir de los años 90 del siglo XX obligaron a aprobar una nueva legislación.

Fue a través de la Ley 39/2003 como se introdujo el nuevo modelo ferroviario basado en la separación entre gestión de infraestructura y prestación de los servicios de transporte. En el artículo $4 .^{\circ}$ de dicha norma se introdujo el concepto de la «Red Ferroviaria de Interés General» (REFIG) que comprendería «las infraestructuras ferroviarias que resulten esenciales para garantizar un sistema común de transporte ferroviario en todo el territorio del Estado» así como las que fueres necesarias para su funcionamiento, poniendo como ejemplo «las vinculadas a los itinerarios de tráfico internacional, las que enlacen las distintas comunidades autónomas y sus conexiones y accesos a los principales núcleos de población y de transporte o a instalaciones esenciales para la economía o la defensa nacional.»

Aun cuando pareciera existir una continuidad o similitud máxima con la anterior RENI, existen ciertas diferencias de calado pues mientras que la RENI de 1987 comprendía tanto infraestructuras como servicios, la REFIG de 2003 sólo alude a las infraestructuras como soporte de la red ${ }^{37}$.

En todo caso, la red es definida mediante una combinación de criterios territoriales y de interés general, basados ambos en la correcta configuración de una red en sentido técnico, como sistema integrado de elementos que permitan el transporte entre los nodos de jerarquía superior (estratégicos para el conjunto del sistema por su ubicación, relevancia económica o conexión internacional).

$Y$ aunque es cierto que en la configuración de ambas redes ferroviarias late la finalidad y el objetivo de establecer un sistema ferroviario común, la Ley 39/2003 expresamente limitó su alcance a la red ferroviaria de titularidad estatal, eludiendo o renunciando -formalmente- a imponer un sistema ferroviario que afectase o vinculase a todos los ferrocarriles presentes en el país. Limitación que respondió a la doctrina establecida por la Sentencia 118/96 del Tribunal Constitucional sobre la que luego volveremos.

Finalmente, la reciente Ley 38/2015 del Sector Ferroviario ha mantenido en su artículo $4 .{ }^{\circ}$ la definición de la REFIG precedente, si bien le ha añadido un último apartado 4 muy significativo conforme al cual «El Estado y las comunidades autónomas con infraestructuras ferroviarias de su titularidad cooperarán para facilitar la conexión entre estas infraestructuras ferroviarias y la Red Ferroviaria de Interés General, fomentando la interoperabilidad entre las diferentes redes».

Esta es la definición actual de la red ferroviaria estatal que claramente incorpora tanto el criterio territorial como el del interés general para atribuir al Estado la competencia sobre dicha red. El paralelaje con los criterios utilizados en las leyes de otros sectores, como el de carreteras resulta evidente y a todas luces buscado de propósito ${ }^{38}$.

Sucede que pese a esa equiparación formal entre red e infraestructura, el régimen jurídico de los servicios de transporte ferroviario tiene sustantividad propia y lo diferencia o aleja de un tratamiento reduccionista a la mera gestión concesionada de una infraestructura en red. En aplicación de la Política Ferroviaria Común, el transporte ferroviario se debe prestar en régimen de libre competencia, con las cautelas al uso, sin eliminar las potestades administrativas de control, pero implantando un sistema basado en el derecho de acceso a la red, en condiciones

36 Martín-Retortillo Baquer (1991); García Perez (1996); MAgdalena (2003).

37 RIVAS CASTILLO, VALCARCEL FERNÁNDEZ (2014): 1110.

38 Compárese con el artículo 4 de la Ley "Son carreteras estatales las integradas en un itinerario de interés general o cuya función en el sistema de transporte afecte a más de una Comunidad Autónoma”, declarado constitucional por STC 65/1998 de 18 de Marzo, y el vigente artículo 4.4 de Ley 37/2015, de carreteras ("Constituyen la Red de Carreteras del Estado las integradas en un itinerario de interés general o cuya función en el sistema de transporte afecte a más de una comunidad autónoma"), enumerando ambas normas como carreteras de titularidad estatal aquéllas que formaban parte de itinerarios internacionales, den acceso a puertos o aeropuertos de interés general, etc.

REALA, Nueva Época, - N. 5, enero-junio 2016 - ISSN: 1989-8975 - DOI: 10.24965/reala.voi5.10346 
de igualdad, concurrencia y transparencia. El transporte ferroviario debe regularse y evaluarse sobre estos parámetros, pues la red de servicios tiene sustantividad propia más allá del régimen específico de la infraestructura que le sirve de soporte.

\section{LA DEMORADA CONCRECIÓN DE LA RED FERROVIARIA ESTATAL. CATÁLOGO DE LA RED Y DECLARACIÓN SOBRE LA RED}

El legislador español mantuvo sin concretar el contenido real, físico, de la red ferroviaria nacional desde 1987 hasta 2015, haciendo uso de una técnica normativa más que discutible.

Concretamente, por sendas disposiciones adicionales (la octava de la LOTT y la novena de la Ley 39/2003) se estableció que la Red Ferroviaria de titularidad estatal comprendería todas las infraestructuras ferroviarias que a la fecha de entrada en vigor de cada norma estuvieran siendo administradas por el operador público estatal (RENFE, el Gestor de Infraestructuras Ferroviarias luego sustituido por el ADIF o la Autoridad Portuaria correspondiente); disponiendo el mandato al Gobierno para que concretase luego los servicios y líneas que debían integrarse en esa red estatal. Como es habitual en nuestro país, lo provisional devino definitivo, y transcurrieron lustros sin aprobarse tal concreción de la red ferroviaria estatal.

Sólo cuando la Sentencia 245/2012 del Tribunal Constitucional declaró inconstitucional la Disposición Adicional Novena de la Ley 39/200339, el legislador se avino a poner fin a semejante situación que por la vía de los hechos había petrificado la red ferroviaria desde hacía casi 28 años (sin contar el periodo 1978-1987).

Por Real Decreto-Ley 4/2013, de 22 de Febrero, y, posteriormente, mediante la Ley 11/2013, de 26 de Julio, se dio una nueva redacción a la Disposición Adicional Novena de la Ley 39/2003 con el mandato al Ministerio de Fomento para que en seis meses estableciera el Catálogo de Líneas y Tramos de la Red Ferroviaria de Interés General conforme a los criterios establecidos en el artículo $4 .^{\circ}$ de la Ley.

Con la demora tradicional en nuestra política ferroviaria, el Ministerio de Fomento dictó la Orden FOM/710/2015, de 30 de Enero por la que se aprobó el Catálogo de líneas y tramos de la Red Ferroviaria de Interés General. Documento del cual conviene trascribir, por su claridad, el siguiente párrafo:

«Conviene también resaltar que todas las líneas y tramos incluidos en el presente Catálogo mantienen entre sí una clara relación funcional ferroviaria, de manera que las acciones, que puedan llevarse a cabo en cada uno de dichos tramos, muestran efectos de diverso alcance en el resto. Por todo ello, se ha estimado conveniente tener muy en cuenta la posible existencia de estas interdependencias y su consideración conjunta en una misma red, a la hora de establecer el Catálogo.»

Se está reconociendo un diseño de la red ferroviaria ajustado a la noción de red antes comentada, como conjunto integrado de nodos y conexiones orientados a un fin (el transporte a escala nacional.

Más allá de la infraestructura lo relevante es el diseño de la red misma, entendida como relación funcional de servicios de transporte, de manera tal que un simple tramo ferroviario puede carecer de relevancia física aparente, pero soportar un nivel de conexión estratégico. Cierto es que el examen del Catálogo produce la impresión de haberse integrado prácticamente todas las líneas existentes en funcionamiento, o al menos la inmensa mayoría, pero ello es ya una cuestión técnica a impugnar o negociar por las Comunidades Autónomas que deseen impulsar o ampliar sus propias redes regionales (algo improbable por razones presupuestarias obvias).

Para finalizar ese apartado ha de hacerse una sucinta referencia a un instrumento jurídico específicamente creado para el sector ferroviario, con una importancia capital en el nuevo modelo basado en la disociación entre infraestructura y vehículo: la Declaración sobre la red, regulada tanto en la Ley 39/2003 como en la Ley 38/2015 del Sector Ferroviario, y desarrollado su contenido mediante la Orden FOM/897/2005, de 7 de abril, relativa a la declaración sobre la red y al procedimiento de adjudicación de capacidad de infraestructura ferroviaria.

De factura comunitaria ${ }^{40}$, se trata de un documento esencial para facilitar el acceso al mercado de los servicios ferroviarios, pues describe y detalla las condiciones y características técnicas la red ferroviaria abierta a los operadores de transporte. Se elabora anualmente por el Administrador de la Infraestructura y debe ofrecer de

39 Recogiendo así un clamor de los expertos del sector dada la burla que tal maniobra implicaba respecto de una verdadera apertura del sector ferroviario como mandataba la Política Ferroviaria Común. El Tribunal Constitucional sentenció que una disposición semejante había introducido un criterio subjetivo de atribución competencial manifiestamente incompatible con los criterios constitucionalmente determinados.

40 Directiva 2001/14/CE1, del Parlamento Europeo y del Consejo, de 26 de febrero de 2001, cuyo contenido en este aspecto ha sido recogido y mejorado en la Directiva 2012/34/UE del Parlamento europeo y del Consejo de 21 de noviembre de 2012.

REALA, Nueva Época, - N. ${ }^{\circ}$ 5, enero-junio 2016 - ISSN: 1989-8975 - DOI: 10.24965/reala.voi5.10346 
manera actualizada y transparente y toda la información relevante que permita a los interesados solicitar la adjudicación de capacidades de infraestructura ${ }^{41}$.

Pero su contenido no es estrictamente informativo, como pudiera parecer, sino que contienen la descripción del procedimiento de adjudicación de capacidad (conforme a unos criterios preestablecidos que deben ser no discriminatorios ${ }^{42}$ ), la descripción de los servicios que prestan los Administradores de Infraestructuras, las tasas y cánones ferroviarios, así como las tarifas por la prestación de servicios adicionales y complementarios.

En suma este documento tanto informa como regula y por ello tiene, al menos parcialmente, naturaleza normativa ${ }^{43}$. Al incluir o excluir líneas, tramos y servicios está concretando, administrativamente, el objeto de adjudicación de la capacidad de infraestructura, y el nivel de acceso a la red ferroviaria. La relevancia del documento queda patente en el reciente «Informe relativo a las declaraciones sobre la red 2016 de ADIF y ADIF alta velocidad» de 21 de Enero de 2016 emitido por la Sala de Supervisión Regulatoria de la Comisión Nacional de Mercados y la Competencia ${ }^{44}$, exigiendo el necesario complemento de los contenidos publicados en la Declaración sobre la red para 2016, pues el contenido mínimo de dicho documento fue ampliado por mor de la Directiva 2012/34/UE traspuesta con la Ley 38/2015 45 .

Cumple señalar, por último, que mediante esta descripción anual de la red de servicios disponibles, que varían de un ejercicio a otro, queda aún más en evidencia el carácter instrumental de la infraestructura en red que le sirve de soporte y la esencialidad de los servicios en sí.

\section{EL IMPACTO TERRITORIAL DE LA RED FERROVIARIA Y LA NECESARIA COORDINACIÓN DE LAS REDES ENTRE LAS ADMINISTRACIONES TERRITORIALES}

El ferrocarril impacta necesaria y directamente en el desarrollo económico y social de los territorios por donde discurre y donde se construyen las diversas infraestructuras que componen la red ferroviaria (estaciones de pasajeros, terminales logísticas, talleres, conexiones portuarias, etc.).

La elección de la ubicación concreta de una estación de viajeros o intermodal o la solución técnica del trazado urbano de la línea férrea, condicionarán el urbanismo de la población de que se trate. El tratamiento como nudo ferroviario o punto de conexión a instalaciones portuarias o logísticas de un enclave determinado supondrá la reactivación económica de ese lugar, con el teórico incremento de tráficos (terrestres o de otros modos como los portuarios) y actividades complementarias o auxiliares a los servicios de transporte. La definición de ciertas rutas como corredores principales afectará a la movilidad de las poblaciones conectadas (tanto las de origen-destino como las intermedias), aun cuando su impacto real sea de difícil valoración, e incluso puede resultar negativo en ciertas ocasiones ${ }^{46}$. Las infraestructuras ferroviarias de nueva creación provocan un efecto estructurante del territorio donde se implantan, tanto a nivel local, urbano, como regional e incluso nacional. La apertura de una línea nueva puede captar usuarios de otros modos de transporte, incrementar las relaciones comerciales entre dos urbes pero también polarizar la actividad económica en un polo determinado en detrimento de otros nodos intermedios.

Todos esos ejemplos ponen de relieve que el análisis del ferrocarril desborda el estricto ámbito de las competencias sobre el transporte, debiendo considerarse su impacto en la planificación de las obras públicas, la ordenación del territorio, el medio ambiente y el urbanismo.

Eso debería obligar a las Administraciones Públicas a considerar las redes ferroviarias como algo más que infraestructuras lineales para el flujo de tráficos, debiendo valorarse los potenciales conflictos por intereses legítimos de las distintos sujetos concernidos (tanto la población como el tejido empresarial). No es lo mismo diseñar la red desde la óptica del transporte que desde la perspectiva singular de los nodos conectados o a conectar, algunos de los cuales tendrán un interés absolutamente lógico en obtener la máxima jerarquía dentro de la red.

41 Se trata de los conocidos como "surcos" o franjas horarios durante las cuales pueda un tren circular entre dos puntos de una línea o tramo de línea.

42 Algo esencial si la red ha de abrirse a la competencia, con la concurrencia de varias empresas ferroviarias, debiendo articularse reglas para priorizar las solicitudes, resolver problemas de congestión, prever incidencias, etc.

43 CARBONELl PORRAS (2014) pág. 935.

44 http://www.cnmc.es/Portals/o/Ficheros/Transporte_Postales/Informes\%20Ferrocarril/160121_STP_DTSP_001_16.pdf, último acceso el 17-02-2016.

45 Cierto es que dada la premura con que se tramitó y aprobó la citada Ley, publicada en el BOE de 30 de Septiembre, era prácticamente imposible que los servicios técnicos de ADIF pudieran adaptar el documento que tenían ya ultimado para su publicación a finales de ejercicio, sin perjuicio de haber anunciado ya la necesaria actualización en el semestre inmediato siguiente.

46 Hernández (2010); Bellet SANFeliu, CASellas, Alonso logroño (2010): 143-163; López Pita (1996): 63-83.

REALA, Nueva Época, - N. 5, enero-junio 2016 - ISSN: 1989-8975 - DOI: 10.24965/reala.voi5.10346 
La coordinación en la planificación y gestión de las redes ferroviarias resulta esencial e ineludible, sin que sean factibles posicionamientos exclusivistas. Parece claro que el juego de competencias entre las Administraciones territoriales será siempre complejo y muy probablemente deba resolverse en los casos más enconados, donde las técnicas de cooperación no lleguen, mediante la doctrina de la competencia prevalente ${ }^{47}$.

El problema es que precisamente la Constitución de 1978 impuso como criterio distributivo aparentemente único el territorial. Una cuestionada y cuestionable elección sobre la que versa el siguiente apartado.

\section{LA DOCTRINA DEL TRIBUNAL CONSTITUCIONAL: SSTC 118/96 Y 245/2012. LA NOCIÓN DE RED SUBYACENTE EN LA TEORÍA DE LOS TRAMOS FRAGMENTARIOS}

No es este lugar para comentar la problemática competencial del ferrocarril, que ha sido objeto de varios estudios monográficos ${ }^{48}$, existiendo escasas discrepancias en la doctrina al respecto. Sin embargo, el análisis del concepto de red ferroviaria exige considerar hasta qué punto la noción de red tiene encaje y de qué modo en nuestro sistema constitucional de competencias.

Resulta ya casi tradicional referir el inadecuado tratamiento del ferrocarril en el texto constitucional en sus artículos 148.1.5. ${ }^{\mathrm{a}}$ y 149.1.21. ${ }^{\mathrm{a}}$, tanto en lo formal como en lo sustantivo.

En lo formal, por cuanto que hace un uso ambiguo del término polisémico «ferrocarril» conjuntamente con las expresiones «transportes terrestres» y «transporte». Así, mientras en el artículo 148 se emplea una fórmula analítica (equivalente a sólo infraestructura), en el artículo 149 se emplea parecer usar una fórmula sintética por la cual el término «ferrocarriles» alude a la unidad infraestructura-material móvil.

En todo caso, la crítica más relevante es sustantiva, por haber impuesto como criterio distributivo el territorial. Es decir, para la Constitución de 1978 ha de estarse al radio de acción de la infraestructura y el itinerario del transporte ferroviario, de manera tal que correspondería al Estado todo lo que rebase los límites de una Comunidad Autónoma y a ésta lo que discurra en su interior. Eso evidencia una concepción del transporte arcaica y ajena a la realidad socioeconómica, casi diríase que propia de una sociedad preindustrial y así lo consideró la mayoría de la doctrina desde un primer momento.

Y a pesar de ello, o precisamente por la literalidad de la norma constitucional, lo cierto es que en las dos únicas ocasiones que el Tribunal Constitucional se ha pronunciado sobre el transporte ferroviario ha consagrado y enfatizado el criterio territorial como criterio principal, ineludible. Así lo estableció con carácter general para el transporte terrestre en la Sentencia 118/96 («el criterio territorial se configura como elemento esencial en el sistema de distribución de competencias de transportes terrestres.») ${ }^{49}$ y lo ha reiterado con carácter específico para el ferrocarril en la Sentencia 245/2012, aunque complementándolo con el criterio del interés general, pues «a las infraestructuras ferroviarias, en consecuencia, les es aplicable la doctrina que sobre la delimitación de competencias en la materia "obras públicas de interés general"》(F.J.4).

Ahora bien, un examen conjunto de ambas Sentencias del Tribunal constitucional permite identificar unas reglas o precisiones jurídicas que, en conjunto, superan aquel estricto criterio territorial y ajustan la norma a la realidad socioeconómica que se enjuicia.

Para comenzar el Tribunal Constitucional ha advertido que el transporte es una materia con entidad propia y diferenciable de la infraestructura y que la competencia sobre el transporte no atrae en principio a la relativa a la infraestructura (FJ 5), ni viceversa, pues se trata de funciones públicas diferenciadas, lo cual es en sí un avance.

Criterio territorial que es el primordial pero que no elimina ni impide el juego de otras competencias (estatales o autonómicas) que inciden sobre el fenómeno ferroviario, competencias concurrentes que se fundamentan en otros títulos como pueden ser las obras públicas de interés general, la ordenación económica, la seguridad industrial, la ordenación del territorio, etc. Bien entendido que esas competencias concurrentes no pueden desplazar ni relegar totalmente al criterio territorial, sino que aquéllas deberían ser aplicadas como excepción o mediante técnicas de coordinación. No cabe la sustitución del criterio territorial por el de interés general a la hora de aplicar el reparto de competencias.

47 Conforme a la cual, aun cuando no existe una relación jerárquica entre competencias estatales y autonómicas, el Estado no puede verse privado del ejercicio de sus competencias exclusivas por las también exclusivas de una Comunidad Autónoma, pudiendo adoptar la decisión final al respecto (STC 204/2002 de 31 de Octubre, que contiene una recensión de la doctrina sobre competencias concurrentes y sobre la noción de competencia prevalente).

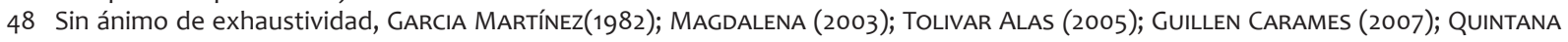
LóPEZ, CASAREs MARCos (2014).

49 Una crítica específica a la STC 118/96 en MAGDALENA (2003): 139-177.

REALA, Nueva Época, - N. ${ }^{\circ}$ 5, enero-junio 2016 - ISSN: 1989-8975 - DOI: 10.24965/reala.voi5.10346 
De manera particular, la Sentencia 245/2012 reconoce que en la definición legal de la REFIG se introduce el criterio del interés general, como superador del estricto ámbito físico o territorial. Se reconoce entonces que la materia está sometida a un doble canon: el de territorialidad y el del interés general, en el entendimiento de que el criterio del interés general complementa y modula el puramente territorial pero sin excluirlo.

El contraste de esa doctrina constitucional con la vigente regulación de la red ferroviaria estatal (el artículo $4 .^{\circ}$ Ley 38/2015) forzosamente habrá que concluir que todo sigue igual dado que la vigente norma mantiene prácticamente inalterado el contenido de la precedente Ley 39/2003. No existe ninguna variación relevante a efectos de constitucionalidad. Los criterios empleados para considerar una infraestructura integrada en la REFIG y por tanto de competencia estatal continúan siendo los mismos.

Quiere ello decir que se mantienen las críticas y reservas planteadas por la Sentencia 245/2012 al enjuiciar la constitucionalidad de la REFIG de 2003: es admisible en tanto con ella no se pretenda invadir competencias autonómicas ni se busque imponer el criterio del interés general desplazando al criterio territorial, que debe seguir siendo el preferente.

En todo caso, lo más relevante para el presente estudio es la introducción por el Tribunal Constitucional de un criterio delimitador de índole técnico no mencionado en los preceptos constitucionales: la integración en una red ferroviaria.

Efectivamente, en la Sentencia 118/96 se introdujo la expresión «tramos fragmentarios» ${ }^{50}$, bien es cierto que de un modo secundario y no referido expresamente al transporte ferroviario, pero con una fuerza hermenéutica indiscutible al afirmar que serían de competencia estatal los servicios de transporte que aun discurriendo íntegramente por territorio autonómico «constituyen fragmentos de una línea matriz supracomunitaria».

Pues bien, esa idea o reflexión ha sido luego acogida en la Sentencia 245/2012 tanto al abordar la competencia sobre infraestructuras ferroviarias como al tratar la competencia sobre el transporte ferroviario.

Respecto de las infraestructuras afirma el Tribunal Constitucional que «el objeto de las competencias autonómicas sobre ferrocarriles debe ser acotado por la concurrencia de una doble condición: se trata de tramos o partes de las vías férreas que, aunque nazcan o mueran fuera de la Comunidad en su itinerario total, discurren dentro de la Comunidad (condición positiva), siempre que el tramo en cuestión no forme parte de una infraestructura ferroviaria considerada de interés general por el Estado (condición negativa)» (F.J. 6 in fine).

$\mathrm{Y}$ respecto del transporte ferroviario, tras recordar la plena aplicabilidad del criterio territorial y la rigidez del mismo, introduce una precisión relativa «a los servicios parciales que constituyen fragmentos de una línea regular supracomunitaria» ${ }^{51}$, a modo de límite para la competencia autonómica. Cierto es que en los párrafos siguientes la Sentencia trae a colación su doctrina sobre los servicios discrecionales, mas ello debe entenderse como ejemplificación de la idea subyacente: la competencia se atribuirá en función de la integración o no del transporte dado en una red «de alcance nacional, independientemente del lugar de carga y descarga».

Se observa un subrepticio cambio doctrinal por el cual no se aplica ni el criterio territorial ni el del interés general, sino un tercer género basado en la integración o no de cada línea o servicio en una red de ámbito superior. Ciertamente puede afirmarse que la verificación de la red en que se integre el transporte es una manifestación del criterio del interés general, una suerte de modalidad específica de ese criterio para una industria en red como es el ferrocarril.

Sin embargo, parece más preciso afirmar que la noción de red per se es suficiente para delimitar o complementar el criterio distributivo de competencias en materia de ferrocarriles. Una tesis, por lo demás, que había sido propuesta en fecha tan lejana como 1979 por COSCULLUELA MONTANER ${ }^{52}$, considerando además el ejemplo real del Estatuto de Autonomía de Galicia, cuyo artículo 27.8 hizo depender la competencia exclusiva sobre ferrocarriles (tanto infraestructuras como transporte ferroviarios) a la condición negativa de estar incorporados «a la red del Estado».

Un transporte ferroviario de alcance regional o local escaparía a la competencia autonómica por razón de su integración en la red ferroviaria estatal. Circunstancia que obligaría a valorar con rigor, y conforme a los conceptos técnicos ya expuestos sobre las redes, el diseño de la red ferroviaria en concreto. Debería analizarse qué importancia concreta tiene cada línea, cada tramo y cada servicio ferroviario en la red como conjunto. Qué tráficos son esenciales y qué nodos son los principales, identificando las prioridades y objetivos estratégicos de la red ferrovia-

50 F.J. 56 y 57 que también emplean los términos "servicios parciales", "matriz" e "hijuelas", todos ellos muy significativos.

51 STC 245/2012, F.J. 16 con cita y referencia al contenido de la STC 118/96.

52 COSCULLUELA MONTANER (1979).

REALA, Nueva Época, - N. ${ }^{\circ}$ 5, enero-junio 2016 - ISSN: 1989-8975 - DOI: 10.24965/reala.voi5.10346 
ria en cuestión. Ello permitiría analizar críticamente si la inserción o exclusión de cada elemento (línea o servicio) resulta justificada y razonable.

Sólo de esta manera, por cierto, se podrá poner coto al riesgo que la teoría de los tramos fragmentarios lleva implícito: si es el Estado el que define qué forma parte de la red ferroviaria estatal, incluso eludiendo el criterio territorial, el ámbito competencial de las Comunidades Autónomas sobre el ferrocarril quedaría vaciado de contenido.

\section{CONSIDERACIONES FINALES}

En el presente trabajo se ha abordado el estudio del ferrocarril desde una perspectiva interdisciplinar, analizando lo que consideramos el rasgo definidor de ese modo de transporte: su carácter sistémico y condición de red. Una cualidad que ha sido ignorada por el constituyente, y que no ha merecido la atención debida por la doctrina.

El ferrocarril es un sistema complejo, integrado por un conjunto de elementos diversos ordenados entre sí hacia un fin (permitir el transporte). En tanto que sistema es una red, y ello permite utilizar los conceptos y técnicas propias de la Teoría General de Sistemas.

Definiría la red ferroviaria como un conjunto de nodos (puntos de origen y destino) conectados por rutas (establecidas sobre las líneas férreas), sobre los cuales se desarrolla organizadamente la circulación de viajeros y mercancías haciendo uso de los medios adecuados (material rodante). Cabe referirse tanto a la red de un modo global (conjunto organizado de servicios e infraestructuras) como segmentado, redes de transporte e infraestructuras en red. Lo esencial es la idea dinámica de organización integrada de elementos.

Por su condición de red resultan consustanciales a la red ferroviaria los requerimientos de conectividad, jerarquía y coherencia. De lo cual se desprende que el diseño de la red de transporte, en tanto que formulación de un modelo, deviene esencial pues ello condiciona la funcionalidad, alcance y potencialidad de la red misma.

Se ha expuesto, además, cómo las redes ferroviarias se vertebran en diversos niveles en función de su alcance territorial, existiendo un objetivo a nivel europeo de favorecer la interoperabilidad de las redes nacionales (trasunto del requisito de coherencia). Es consustancial a la noción de red la superación de barreras y la integración entre redes del mismo o distinto modo, creando cadenas de transportes de especial relevancia para el desarrollo económico, urbanístico y territorial.

Estos conceptos, de naturaleza técnica, permiten un análisis del fenómeno ferroviario que supere la tendencia de la doctrina y la legislación de reducir lo ferroviario a la infraestructura, aun cuando la califiquen como infraestructura en red. No se discute la especial relevancia que las infraestructuras ferroviarias tienen, y que justifica un régimen jurídico especial. Lo que se propugna es que en la formulación y aplicación del régimen jurídico del ferrocarril debe tomarse en consideración su carácter sistémico y de red, capaz de convertirse por sí solo en un criterio de hermenéutica jurídica. Los servicios de transporte ferroviario precisan de un régimen jurídico específico, basado en las nociones de acceso a la red, conectividad de los servicios y competencia por los tráficos, sin menoscabar las potestades administrativas de regulación y de gestión de las infraestructuras que soportan los tráficos.

Desde el punto de vista jurídico, la regulación ferroviaria en España ha sido cuando menos desigual y en ciertos aspectos manifiestamente inadecuada. Aunque el legislador español ha intentado defender un modelo unificado de la red ferroviaria, para garantizar un sistema común de transportes, el Tribunal Constitucional ha rechazado reiteradamente tal pretensión, reafirmado -en principio- un sistema fragmentario de competencias sobre el ferrocarril, basado en el criterio territorial.

Ahora bien, en los apartados anteriores se ha podido demostrar cómo esa aparente rigidez constitucional ha sido finalmente superada mediante la introducción por el Tribunal Constitucional, fundamentalmente en la STC 245/2012, del criterio de integración en una red ferroviaria de ámbito estatal. La realidad, la propia naturaleza del ferrocarril, se ha impuesto a las construcciones dogmáticas que prescindían del carácter sistémico de este modo de transporte.

\section{BIBLIOGRAFÍA}

ARTOLA M., Los ferrocarriles en España (1844/1943), dos vols., Servicio de Estudios del Banco de España, 1978. AA.VV., 150 años del ferrocarril en España, Anaya-Fundación de los Ferrocarriles Españoles, 1998.

Ariño Ortiz, G., LóPez De CAStro García-Moreno, L., «Regulación del transporte», en Principios de Derecho Público Económico. Modelo de Estado, Gestión Pública, Regulación Económica, ARIÑo OrTIz (Dir.), Granada, Comares Ed., 2004. 
BATTEN, David; CASTI, John; ThORD, Roland (ed.), Networks in action: Communication, economics and human knowledge. Springer Science \& Business Media, 2012.

BERMEJO VERA, J., “Empresas ferroviarias y agentes prestadores del transporte. El derecho de Acceso”, en Infraestructuras ferroviarias del tercer milenio, MONTORO CHINER, M.J., Barcelona, Cedecs, 1999.

CARBOnell PorRAS, E., “Infraestructuras de transporte terrestre y sector público estatal”, en Régimen jurídico del transporte terrestre: carreteras y ferrocarriles, MENÉNDEZ, P. (Dir.), tomo I, págs. 916-919, Ed. Aranzadi, 2014.

De Rus, G., CAmpos, J., NombelA, G., Economía del Transporte, Barcelona, Antoni Bosh, 2003.

DE RUS, G., “Integración, competencia y regulación en las redes de transporte. Ekonomiaz: Revista vasca de economía, n. ${ }^{\circ} 46,2001$.

GARCíA CuAdRADO, A., "Notas sobre la teoría general de sistemas", Revista General de Información y Documentación, vol. 5, n. ${ }^{\circ} 1$ (1995), Servicio Publicaciones UCM, Madrid.

GARCíA DE ENTERRÍA, E., “El servicio público de los transporte urbanos”, RAP n. 10 (1953).

GARCíA MARTínEZ, E., “El sistema de transportes ante el nuevo modelo de Estado" en El Estado de las autonomías y el sistema de transportes, Madrid, IETC, 1982.

GARCía PÉREZ, J., Régimen jurídico del transporte por ferrocarril, Marcial Pons, Madrid 1996.

GUILLÉN CARAMES, J., “La ordenación territorial del sector ferroviario” en El Régimen Jurídico del Sector Ferroviario, J. GUILLÉN (Dir.), Thomson Aranzadi, 2007.

GutiéRrez Puebla, J., “Redes, espacio y tiempo”, Anales de Geografía de la Universidad Complutense, 1998, n. ${ }^{\circ}$ 18: 65:86.

KosCHATZKY, Knut. "Fundamentos de la economía de redes: especial enfoque a la innovación”, Economía industrial, 2002, n. ${ }^{\circ} 346$.

LÓPEZ-JURADO, F.B., “Técnicas específicas de los servicios en red” en Derecho de la Regulación Económica, vol. I, MuÑoz MACHAdo, S.- EsteVe PARDo, J. (Dir.), Madrid, lustel, 2009.

MAGdAlenA, J.A., Ferrocarril y competencias de las Comunidades Autónomas, Cálamo Ed., Barcelona, 2003.

MARtín-Retortillo BAQUer, L., "Transportes" en Derecho Administrativo Económico, vol. II, MARTIN-RETORTILLO BAQUER, S., La Ley, Madrid, 1991.

MuÑOZ MACHADO, S. "Fundamentos e instrumentos jurídicos de la regulación económica" en Derecho de la Regulación Económica, vol. I, MuÑoz MACHAdo, S., ESTEVE PARDO, J. (Dir.), Madrid, lustel, 2009.

Olmedo GayA, A., El Nuevo Sistema Ferroviario y su Ordenación Jurídica, Aranzadi, 2000.

QUINTANA LÓPEZ, T., CASARES MARCOS, A., "Distribución de competencias en materia de transporte terrestre entre Estado, Comunidades Autónomas y Corporaciones Locales", en Régimen jurídico del transporte terrestre: carreteras y ferrocarril, tomo I, MENÉNDEZ, P. (Dir.), Aranzadi, 2014.

RIVAS CASTILLO, M.I.- VALCÁRCEL FERNÁNDEZ, P., “Las infraestructuras del transporte terrestre (II): infraestructuras ferroviarias", en Régimen jurídico del transporte terrestre: carreteras y ferrocarril, tomo I, MENÉNDEZ, P. (Dir.), Aranzadi, 2014.

SANTAMARÍA PASTOR, J.A., Fundamentos de derecho administrativo, I, Centro de Estudios Ramón Aceres, 1991.

SolanA Álvarez, J.A., Orero GimÉnez, A., “Economías sometidas a efectos de red”, Anuario Jurídico y Económico Escurialense, XLI (2008).

TOLIVAR ALAS, L., “La distribución competencial en el marco del sector ferroviario” en La liberalización del ferrocarril en España. Una aproximación a la Ley 39/2003 del Sector Ferroviario, MAGDALENA J.A. (Coord.), Ed. Reus, Madrid, 2005.

VOIGT, F., Economía de los sistemas de transporte, Fondo de Cultura Económica, Méjico, 1964. 